\title{
Erratum to: Reliability of frontal sinus by cone beam-computed tomography (CBCT) for individual identification
}

\author{
Gianguido Cossellu $^{1} \cdot$ Stefano De Luca ${ }^{2,5} \cdot$ Roberto Biagi $^{1} \cdot$ Giampietro Farronato $^{1}$. \\ Mariano Cingolani $^{3} \cdot$ Luigi Ferrante $^{4} \cdot$ Roberto Cameriere $^{2}$
}

Published online: 18 July 2015

(C) Italian Society of Medical Radiology 2015

\section{Erratum to: Radiol Med}

DOI 10.1007/s11547-015-0552-y

In the original publication, except the second author's name, the first and last names of all the authors were interchanged. The correct names of the authors should read as follows:

Gianguido Cossellu, Stefano De Luca, Roberto Biagi, Giampietro Farronato, Mariano Cingolani, Luigi Ferrante, Roberto Cameriere.

The original article has been updated accordingly.

The online version of the original article can be found under doi:10.1007/s11547-015-0552-y.

Stefano De Luca

sluca@ugr.es

1 Department of Biomedical, Surgical and Dental Sciences,

Unit of Orthodontics and Pediatric Dentistry, University

of Milan, Fondazione IRCCS Cà Granda Ospedale Maggiore

Policlinico, Milan, Italy

2 AgEstimation Project, Institute of Legal Medicine, University of Macerata, Macerata, Italy

3 Institute of Legal Medicine, University of Macerata, Macerata, Italy

4 Department of Biomedical Sciences and Public Health, Faculty of Medicine, Polytechnic University of Marche, Ancona, Italy

5 Calle las moreras 77, 29871 Griñón, Madrid, Spain 